\title{
EFFECTS OF SIEVE APERTURE MODIFICATION ON DEWATERED CASSAVA MASH SIEVING PROCESS
}

\author{
A. A. Ahiakwo ${ }^{1, *}$, K. J. Simonyan ${ }^{2}$ and A. B. Eke ${ }^{3}$ \\ 1, Dept. of Agricultural Education, Fed. College of Education (TeCh.) Omoku, Rivers State, nigeria \\ 2,3, Department Agricultural and Bioresources EngineERING, Michael OKPaRA UNiVERSity OF \\ AGRICULTURE, UMUDIKE, ABIA STATE, NIGERIA \\ E-mail addresses: ${ }^{1}$ a.ahiakwo@yahoo.com, ${ }^{2}$ omogbeka@gmail.com, ${ }^{3}$ akafav@yahoo.com
}

\begin{abstract}
Dewatered cassava mash (DCM) sieve aperture is fixed arbitrarily at $3 \mathrm{~mm}$ by local craftsmen. This contributes to high energy and time consumption. This research focused on modifying this aperture experimentally and to assess its effect on sieving time, throughput capacity, and particle size dimension. Sieving was done with four replications using $2 \mathrm{~kg}$ DCM across $3 \mathrm{~mm}, 5 \mathrm{~mm}$ and $7 \mathrm{~mm}$ apertures. The result showed throughput capacity of $35 \mathrm{~kg} / \mathrm{h}, 59 \mathrm{~kg} / \mathrm{h}$ and $84 \mathrm{~kg} / \mathrm{h}$ respectively. The Anova, at 5\% shows a significant difference among the means of the throughput capacity. Also, effective size $D_{10}$ of garified sample, fineness modulus and average particle size of the sieves were close. The $t_{c a l}$ for the particles from $3 \mathrm{~mm}$ compared to $5 \mathrm{~mm}$ and $7 \mathrm{~mm}$ sieve were 0.61 and 1.1 respectively whereas the $t_{\text {crital }}$ was 2.15 showing that the particle sizes do not differ significantly. Sieve aperture can be modified to between $5 \mathrm{~mm}$ to $7 \mathrm{~mm}$ inclusive with good results.
\end{abstract}

Keywords. Sieve, Aperture, Dewatered Cassava Mash, Throughput Capacity

\section{INTRODUCTION}

Sieving operation is an important unit operation in garri processing. It is a size reduction and separation process in which the sieve is the active element. The sieve design in terms of mesh count and aperture has a feedback effect on the processors comfort or discomfort especially in traditional method of sieving and also on throughput capacity and machine efficiency in terms of mechanized sieve.

Sieving is done manually using sieves made from palm leaves, bamboo or raffia cane [1], it is a mechanical process which stratifies particles according to size [2]. A sieving media or surface is a sieving medium with predetermined openings used to classify two fractions of a feed material. It consists of forcing the mixture through a screen of a specific size aperture [3]. Mesh represents the sieve size of standard sieve. It is the holes number in $25.4 \mathrm{~mm}$ which is the mesh count [4]. The larger the mesh size, the smaller the aperture [5]. By decreasing the space between holes, webbing or wire diameter, the open area may be increased, increasing capacity [6].

Ogunsina, et al [7] reported that over $92 \%$ of garri producers still use the traditional raffia sieve for pulverizing and sifting operation. On traditional sieving process, where the operator bends forward to apply a repetitive shearing and compressive force on the dewatered mash against the sieve, it might be true to say that the force exerted by the operator to sieve a given mass increases with a decrease in sieve aperture [2].

The mean sieve aperture currently developed by the local craftsmen for sieving dewatered cassava mash is $2.86 \mathrm{~mm}$ [8]. The local processors who are accustomed to the use of this sieve aperture ignorantly believe that increasing the sieve aperture beyond the approximately $3 \mathrm{~mm}$ aperture will make the garri grain extra coarse and hence unacceptable for consumption. The result is that the processors suffer great discomfort in an attempt to squeeze the DCM through

* Corresponding author, tel: +234-803-877-8669 
the small aperture over a rather longer period of time in an awkward position.

Besides, the primary objective of the sieve as constructed by the local craftsmen is to trap the coarse ungrated particle during sifting of the dewatered lump. With this concept the fixing of sieve aperture, is a decision of the local craftsman who by his imagination and craftsmanship measure out the apertures with his eyes as he knit the individual strip of the raffia together. At the end, an irregular aperture is revealed throughout the sieve. There is no standardization of sieve aperture hence there may be variation depending on who and where it is obtained [8].

However, to reduce the drudgery inherent in traditional sieving process, a number of mechanized sieves have been developed. [9], designed and developed cassava lump breaking and sieving machine. [10], developed and evaluated motorized cassava mash sifter while [11], designed and fabricated an improved garri sifting machine. On the other hand, [12] designed a pedal driven pulverizing and sieving machine, and [13], developed NCAM reciprocating cassava mash sifter. These machines represent earnest efforts at reducing drudgery in cassava processing and enhance productivity. However these designs are silent on the sieve aperture or mesh used in developing them. This presents a challenge in terms of replacement, reproduction and sieve output capacity. This is true because, all other elements held constant, a change in sieve aperture or mesh might result in irregularity of discharged particle size and machine element malfunction.

Garri grain or particle size distribution is an important factor producers of garri give attention to during processing of cassava into garri. This is because the commercial value, appearance and suitability of garri for various purposes is tied in to this factor [14]. Since particle size distribution of garri which tells of the fineness or coarseness is a function of sieve aperture, analyzing the particle size distribution can provide insight as to the best sieve aperture to adopt [15].

This research therefore seeks to experimentally modify locally established sieve aperture as constructed by local developers (Fig.1) and to assess if there is statistically significant difference in the use of the locally fixed sieve aperture and the modified sieve with respect to sieving time, throughput capacity and Garri particle size distribution. In other words the researcher is working on the hypothesis that the particle sizes from the locally developed sieve and that from the modified sieve differ significantly.

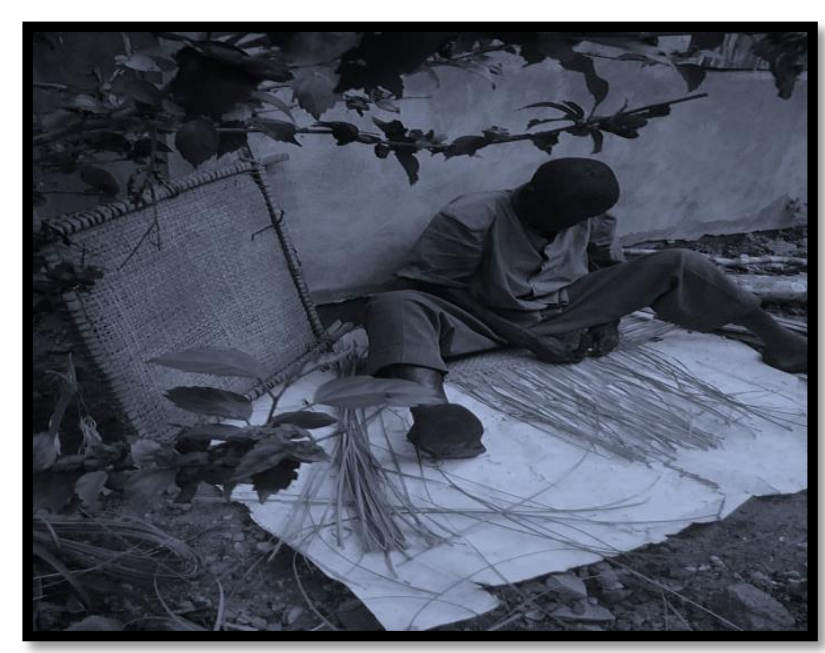

Figure 1: Raffia sieve development by a local craftsman

It is believed that if processors are aware of the discomfort involved, energy and time wasted in the use of the traditional sieve, they may make a change in order to achieve higher productivity at a shortest possible time. This research also points out the need to give sieve aperture due consideration in the design of an improved manual or motorized sieve.

\section{MATERIALS AND METHODS}

\subsection{Materials}

The equipment used for developing the experimental sieves are:
a) A locally developed DCM sieve with $3 \mathrm{~mm}$ sieve aperture
b) Galvanized metal sheet $1 \mathrm{~mm}$ thick
c) Drilling machine
d) Drilling bits - $5 \mathrm{~mm}, 7 \mathrm{~mm}$
e) Engineers square
f) Scriber
g) Centre punch

\subsection{Development of research sieves}

Each of the experimental sieves was constructed from $1 \mathrm{~mm}$ galvanized metal sheet measuring $450 \mathrm{~mm} \times 350$ $\mathrm{mm}$. Engineers Square was used to square the plate and also guide in scribing horizontal and vertical lines to create inter hole spaces and the square space for drilling the hole. The centre punch was used to make the lines bolder. The drilling machine and bits were used to create round hole squared pitch drill pattern shown in Figure 2. 


\subsubsection{Determination of mesh number}

The mesh number for each of the sieves was determined by selecting an in-between hole spacing that will give a larger open area. $1 \mathrm{~mm}$ spacing was selected because it gave the least possible dimension to accommodate the drilling process while producing higher open area. The plates were marked, punched and drilled using round hole square pitch drill pattern shown in Fig 2.

\subsubsection{Characteristics of experimental sieve}

The two experimental sieves were made of round hole squared pitch drill pattern and was developed with the characteristics shown in Fig 2.

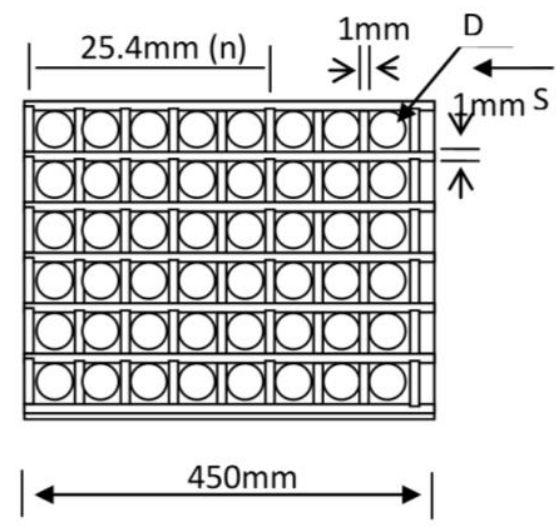

Fig 2: Round hole squared pitch drill pattern of the experimental sieve ( $D$ is the diameter of the experimental sieve aperture and $S$ is the spacing between hole)

The mesh number $\mathrm{n}$ for experimental sieve was obtained from the formula given by [16]:

$$
n=\frac{25.4}{(D+S)}
$$

Here $\mathrm{n}$ is the mesh number; $\mathrm{D}$ is the Diameter (sieve aperture) and $\mathrm{S}$ is the spacing between aperture Also, the percentage open area $A_{0}$ for the experimental sieve was obtained from the formula given by [17]:

$$
A_{0}=\frac{0.785 d^{2}}{(s+d)^{2}} \times 100
$$

where: $A_{o}=$ percentage open area, $d=$ diameter (sieve aperture) and $\mathrm{s}=$ spacing between aperture

\subsubsection{Characteristics of the locally developed sieve}

The locally made sieve was of the woven wire mesh pattern and was developed with the characteristics shown in Fig 3.

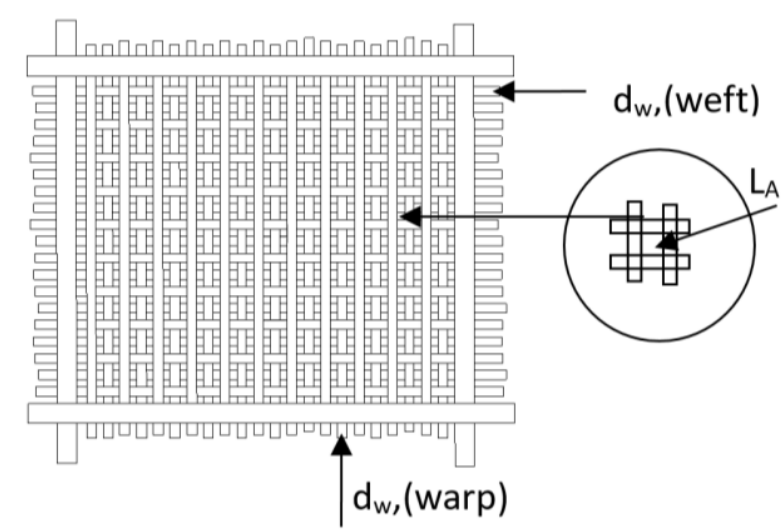

Fig 3: Woven wire mesh pattern of the locally developed sieve $\left(L_{A}\right.$ is the sieve aperture $=3 \mathrm{~mm} ; \mathrm{dw}$ is the Horizontal width of raffia strip $=6 \mathrm{~mm}$ )

Mesh number, $M$ is defined by [16] as:

$$
M=\frac{25.4}{\left(L_{A}+d_{w}\right)}
$$

And Percentage open area, $A_{0}$ is given by [17] as:

$$
A_{o}=\left(\frac{L_{A}}{L_{A}+d_{w}}\right)^{2} \times 100
$$

\subsection{Experimental design}

Randomized complete block design (RCBD) was used for the experimentation. The experiment sought to determine the effect of modifying sieve aperture on sieving time, throughput capacity and particle size distribution. The dependent variable was the sieve size, while the independent variables were sieving time, throughput capacity and particle size distribution. Unit of treatment was $2 \mathrm{~kg}$ of DCM. This was used as a treatment for the different apertures of $3 \mathrm{~mm}, 5 \mathrm{~mm}$ and $7 \mathrm{~mm}$ which were used in constructing the locally developed sieve and the experimental respectively. The sieve of $3 \mathrm{~mm}$ aperture served as control sieve whereas sieves with $5 \mathrm{~mm}, 7 \mathrm{~mm}$ served as experimental sieves. The parameters measured were: sieving time, throughput capacity, and particle size distribution.

Table 1: Sieve aperture and sieving process replication in $R C B D$

\begin{tabular}{cccc}
\hline Block1 & Block 2 & Block 3 & Block 4 \\
\hline $3 \mathrm{~mm}$ & $5 \mathrm{~mm}$ & $7 \mathrm{~mm}$ & $3 \mathrm{~mm}$ \\
$5 \mathrm{~mm}$ & $7 \mathrm{~mm}$ & $3 \mathrm{~mm}$ & $7 \mathrm{~mm}$ \\
$7 \mathrm{~mm}$ & $3 \mathrm{~mm}$ & $5 \mathrm{~mm}$ & $5 \mathrm{~mm}$ \\
\hline
\end{tabular}

\subsection{Experimental procedure}

A processor was requested to use $2 \mathrm{~kg}$ of DCM on each of the sieves and carry out sieving task manually in a normal and accustomed manner. The sieving process 
and replication followed the randomized complete block design shown in Table 1. The time to completely sieve the $2 \mathrm{~kg}$ mash in each case was recorded and replicated 4 times for each of the sieves. The resultant throughput capacity with respect to time was calculated in each case:

$$
T_{p 1 \ldots n}=\frac{Q_{1 \ldots n}}{t_{1} \ldots n}
$$

where: $T_{p_{1} \ldots n}$ is the throughput for the three different sieves; $Q_{1 \ldots n}$ is the quantity sieved and and $\mathrm{t}_{1 \ldots \mathrm{n}}=$ time to sieve the given quantity through the three sieves. To determine the grain size of the sieved particles and its acceptability, sieved samples from the controlled sieve and experimental sieves were subjected to garification. The particle size distribution of garified sample was analysed.

\subsection{Analysis of Sieved Sample for Particle Size Distribution}

Particle size distribution of the sieved DCM was obtained using IS 460 Sethi standard test sieve of diameters $1.70 \mathrm{~mm}, 1 \mathrm{~mm}, 0.85 \mathrm{~mm}, 0.35 \mathrm{~mm}, 0.30$, 0.20 and pan. The test was carried out to determine particle size variation, fineness or coarseness of sieved particle with respect to control and experimental sieves of $3 \mathrm{~mm}, 5 \mathrm{~mm}$ and $7 \mathrm{~mm}$ aperture respectively. The particles obtained from the control and experimental sieves were subjected to two tailed t-test to ascertain if the Garri particles obtained from the control and experimental sieves differ significantly in their sizes.

$300 \mathrm{~g}$ garified sample from each of the researched sieves was loaded on top the test sieve of six stack and pan. This was agitated for 10 minutes after which the weight retained in each of the sieves was recorded for each sample and replicated three times. From the weight retained measured with Pioneer plus analytical electronic balance Cp214, the cumulative weight, cumulative percentage, and fineness modulus were obtained. Also from the distribution curve, the effective sizes of Garri grain, coefficient of uniformity and gradation were obtained.

Percentage retained, $r$, on any sieve was given from the relation expressed by [15] as:

$$
r=\frac{W_{r}}{W_{t}} \times 100 \%
$$

where $W_{r}$ is the weight of gari retained and $W_{t}$ is total weight of gari.

Uniformity coefficient $c_{u}$ was calculated from the relation expressed by $[7,5]$ :

$$
c_{u}=\frac{D_{60}}{D_{10}}
$$

Where $D_{60}$ is diameter corresponding to $60 \%$ finer in the particle size distribution curve.

On the other hand coefficient of gradation $c_{e}$ was calculated from the relation expressed by [15]

$$
c_{e}=\frac{D_{30}^{2}}{D_{10} \times D_{60}}
$$

Where $D_{30}$ is the diameter corresponding to $30 \%$ finer in the particle size distribution.

Average particle size $D_{p}$ was calculated from the relation given by [18]:

$$
D_{p}=0.135(1.366)^{F M}
$$

Where $\mathrm{FM}=$ Fineness Modulus

\section{RESULTS AND DISCUSSION}

Table 2 shows the effect of modifying sieve aperture on sieving time. The mean time in minutes required to sieve $2 \mathrm{~kg}$ of DCM across the traditional sieve (control) and that of the modified sieve (experimental) are: 4.1, 2.6 and 1.5 respectively.

Table 2: Mean time required to sieve $2 \mathrm{~kg}$ of DCM in research sieves

\begin{tabular}{llll}
\hline & $\begin{array}{l}\text { Control } \\
\text { sieve }\end{array}$ & $\begin{array}{l}\text { Experimental } \\
\text { sieve }\end{array}$ \\
\hline Sieve aperture & $3 \mathrm{~mm}$ & $5 \mathrm{~mm}$ & $7 \mathrm{~mm}$ \\
\hline & 4.4 & 2.8 & 1.5 \\
Time (2kg/min) & 4.4 & 2.6 & 1.5 \\
& 3.9 & 2.6 & 1.5 \\
& 3.7 & 2.5 & 1.3 \\
\hline Mean time (minute) & 4.1 & 2.6 & 1.5 \\
\hline
\end{tabular}

This shows that the traditional sieve consumes more time than the experimental sieves for the same quantity of DCM. This time consumption is also connected with the lower percentage open area which permits small quantity of the DCM to pass through the traditional sieve aperture. The results presented in the tables above actually shows the effect of modifying traditional sieve aperture and to what extent the aperture should be increased to.

Table 3 shows the effect of modifying sieve aperture on throughput capacity. From the table, observe that at $3 \mathrm{~mm}, 5 \mathrm{~mm}$ and $7 \mathrm{~mm}$ sieve aperture, the throughput capacities are $39 \mathrm{~kg} / \mathrm{hr}, 59 \mathrm{~kg} / \mathrm{hr}$ and $84 \mathrm{~kg} / \mathrm{hr}$.

From the Table 3, observe also that percentage open area of the locally made sieve is comparatively low whereas that of experimental is comparatively high. 
This is attributed to the material development pattern. The low percentage open area noticed in the locally made sieve can be attributed to the material and development pattern of the sieve which was made by weaving rectangular strips of raffia material. The experimental sieve aperture was established by drilling a round hole with inter-hole spacing of $1 \mathrm{~mm}$. This comparatively small inter hole spacing results in a higher percentage open area and by extension a higher throughput capacity of $84 \mathrm{~kg}$ per hour as oppose to the lower throughput capacity of $39 \mathrm{~kg} / \mathrm{hr}$ obtained by the use of the locally made sieve.

Increasing traditional sieve aperture from $3 \mathrm{~mm}$ to $7 \mathrm{~mm}$ gives a higher throughput capacity $(39 \mathrm{~kg} / \mathrm{hr}$ to $84 \mathrm{~kg} / \mathrm{hr}$ ). However the $5 \mathrm{~mm}$ sieve aperture is recommended though comparatively low in throughput capacity, its particle size proved to be closely related to that obtained using $3 \mathrm{~mm}$ sieve and hence more acceptable than that from the $7 \mathrm{~mm}$ sieve. This is in agreement with Ogunsina, et al [7] who obtained a throughput capacity of $55.46 \mathrm{~kg} / \mathrm{hr}$, while sieving approximately $1 \mathrm{~kg}$ of DCM with $3 \mathrm{~mm}$ raffia sieve, but a throughput capacity of $227.71 \mathrm{~kg} / \mathrm{hr}$ while sieving an average of $1.6 \mathrm{~kg}$ DCM with $5 \mathrm{~mm}$ crank sieve at $67 \mathrm{rev} / \mathrm{min}$. The difference in result is attributed to the fact that this research used $2 \mathrm{~kg}$ and a motorized sieve at 100 revolutions per minute. Although, we use apertures of $3 \mathrm{~mm}$ and $5 \mathrm{~mm}$ respectively, the mesh count and percentage open area may not be the same. However the common ground is that the time of sieve using raffia sieve is high while the throughput is low. By increasing the aperture to $5 \mathrm{~mm}$ the sieving time is reduced with a high throughput capacity.

\subsection{Analysis of variance}

Table 4 shows the result of sieving $2 \mathrm{~kg}$ of DCM on three different sieve apertures replicated four times and the throughput capacity presented in ANOVA table. Table 5, shows the anova of throughput capacity and the result of comparing the control and experimental sieves at different sieve apertures. From table 5, the test statistic is the $F$ value of 4.5 . Using an $a$ of 0.05 , then F.05, $2,9=4.256$. But $F>4.256$, hence there is a statistically significant difference among the population means of the throughput capacity.

\subsection{Particle size distribution of garified sample}

Table 6 to 8, shows the particle size distributions for the control and experimental sieves. Table 6 shows the percentage finer of a garified sample from standard test sieves. For the $3 \mathrm{~mm}$ control sieve, this gives a fineness modulus of 3.37. Table 7 shows the percentage finer of a garified sample from standard test sieves. For the $5 \mathrm{~mm}$ experimental sieve, this gives a fineness modulus of 3.72 . Table 8 shows the percentage finer of a garified sample from standard test sieves. For the $7 \mathrm{~mm}$ experimental sieve, this gives a fineness modulus of 3.90 .

Table 3: Sieve characteristics and throughput capacity

\begin{tabular}{ccccc}
\hline & Diameter $(\mathrm{mm})$ & Mesh number, $\mathrm{n}$ & Open area Ao $(\%)$ & Throughput capacity (kg/hr.) \\
\hline Control sieve & 3 & 3 & 11 & 39 \\
\hline \multirow{2}{*}{ Experimental sieve } & 5 & 4.2 & 55 & 59 \\
\cline { 2 - 5 } & 7 & 3.2 & 60 & 84 \\
\hline
\end{tabular}

Table 4: Throughput capacity (Kg/hr) at different sieve apertures

\begin{tabular}{ccccccc}
\hline \multirow{2}{*}{ Treatment Aperture/2kg } & \multicolumn{4}{c}{ Replications } & \multirow{2}{*}{ Total } & \multirow{2}{*}{ Mean } \\
\cline { 2 - 5 } & 1 & 2 & 3 & 4 & & 141 \\
La1 $(3 \mathrm{~mm})$ & 32 & 33 & 37 & 39 & 35 \\
La3 $(5 \mathrm{~mm})$ & 54 & 55 & 64 & 62 & 235 & 59 \\
La4 $(7 \mathrm{~mm})$ & 84 & 87 & 80 & 85 & 336 & 84 \\
\hline
\end{tabular}

Table 5: ANOVA of throughput capacity

\begin{tabular}{ccccc}
\hline Source of Variation & Sum of square(SS) & DF & Mean Square(MS) & F \\
\cline { 1 - 3 } Treatment & 4,755 & 2 & 67.5 \\
Error & 135 & 9 & 15 & \\
Total & 4,890 & 11 & & \\
\hline
\end{tabular}


Table 6: Fineness modulus of $3 \mathrm{~mm}$ aperture garrified sample

\begin{tabular}{|c|c|c|c|c|}
\hline Sieve Size $(\mathrm{mm})$ & Wt of garri retained $(\mathrm{g})$ & cumu.wt. retained $(\mathrm{g})$ & cumu (\%) retained & \%Finer \\
\hline 1.7 & 12.4 & 12.4 & 4.13 & 95.87 \\
\hline 1.00 & 53.0 & 65.4 & 21.8 & 78.2 \\
\hline 0.85 & 44.5 & 109.9 & 36.63 & 63.37 \\
\hline 0.33 & 134.5 & 244.4 & 81.46 & 18.54 \\
\hline 0.30 & 36.3 & 280.7 & 93.57 & 6.44 \\
\hline 0.20 & 17 & 297.7 & 99.23 & 0.77 \\
\hline \multirow[t]{2}{*}{ Pan } & 2.3 & 300 & Total $=$ & 336.8 \\
\hline & & & $\mathrm{FM}=$ & 3.37 \\
\hline
\end{tabular}

Table 7: Fineness modulus of $5 \mathrm{~mm}$ aperture garrified sample

\begin{tabular}{|c|c|c|c|c|}
\hline Sieve Size $(\mathrm{mm})$ & Wt of garri retained $(\mathrm{g})$ & cumu.wt. retained(g) & cumu (\%) retained & \%Finer \\
\hline 1.7 & 45.4 & 45.4 & 15.13 & 84.87 \\
\hline 1.00 & 58 & 103.4 & 34.46 & 65.54 \\
\hline 0.85 & 36.2 & 139.6 & 46.53 & 53.47 \\
\hline 0.33 & 110.2 & 249.2 & 83.26 & 16.74 \\
\hline 0.30 & 35 & 284.8 & 94.93 & 5.07 \\
\hline 0.20 & 14.2 & 299 & 99.66 & 0.34 \\
\hline \multirow[t]{2}{*}{ Pan } & 1 & 300 & Total = & 372 \\
\hline & & & $\mathrm{FM}=$ & 3.72 \\
\hline
\end{tabular}

Table 8: Fineness modulus of $7 \mathrm{~mm}$ aperture garrified sample

\begin{tabular}{ccccc}
\hline Sieve Size $(\mathrm{mm})$ & Wt of garri retained $(\mathrm{g})$ & Cumu.wt. retained $(\mathrm{g})$ & Cumu (\%) retained & \%Finer \\
\hline 1.7 & 55.5 & 55.5 & 18.5 & 81.5 \\
1.00 & 58.8 & 114.3 & 38.1 & 61.9 \\
0.85 & 41.3 & 155.6 & 51.87 & 44.13 \\
0.33 & 101.7 & 257.7 & 85.77 & 14.23 \\
0.30 & 30.4 & 287.7 & 95.9 & 4.1 \\
0.20 & 11.4 & 299.1 & 99.7 & 0.3 \\
\hline Pan & 0.9 & 300 & Total $=$ & 389.9 \\
& & & FM $=$ & 3.90 \\
\hline
\end{tabular}

Figure 4 show the particle size distribution curve of the garified samples from the three researched sieves under consideration, namely: $3 \mathrm{~mm}, 5 \mathrm{~mm}$ and $7 \mathrm{~mm}$. The percentage finer of the following distributions: $96.37,78.20,63.37,18.54,6.44$ and 0.77 for $3 \mathrm{~mm}$ sieve aperture, 84.87, 65.54, 53.47, 16.74, 5.07 and 0.34 for $5 \mathrm{~mm}$ sieve aperture and $81.50,61.90,44.13$, $14.23,4.1$ and 0.30 for $7 \mathrm{~mm}$, plotted against the particle sizes gave the characteristics of the garri particles shown in Table 9.

From Table 9, the effective particle size $D_{10}$ of garified samples, the fineness modulus and average particle size from the $3 \mathrm{~mm}, 5 \mathrm{~mm}$ and $7 \mathrm{~mm}$ sieve are 0.31 , 0.33 and $0.34 ; 3.37,3.72$ and $3.90 ; 0.39,0.43$, and 0.46 respectively. Observe that the effective sizes $D_{10}$ for the three sieves are very close. It can also be observed that there is a progressive increase in fineness modulus (FM) from $3 \mathrm{~mm}$ to $7 \mathrm{~mm}$ sieve sizes but this does not translate to a large difference in their average particle size Dp.

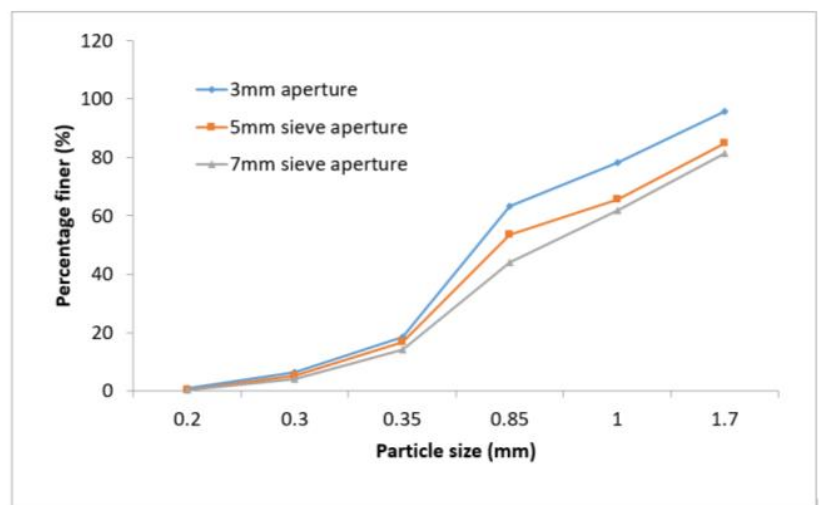

Figure 4: Particle size distribution of garified sample from different sieve aperture 
Table 8: Characteristics of particle size distribution for garified samples

\begin{tabular}{cccccccc}
\hline Sieve size & $\mathrm{D}_{10}$ & $\mathrm{D}_{30}$ & $\mathrm{D}_{60}$ & $\mathrm{FM}$ & $\mathrm{Cu}$ & $\mathrm{Ce}$ & $\mathrm{D}_{\mathrm{p}}$ \\
\hline $3 \mathrm{~mm}$ & 0.31 & 0.47 & 0.79 & 3.37 & 2.55 & 0.90 & 0.39 \\
$5 \mathrm{~mm}$ & 0.33 & 0.54 & 0.94 & 3.72 & 2.85 & 0.94 & 0.43 \\
$7 \mathrm{~mm}$ & 0.34 & 0.62 & 0.99 & 3.90 & 2.91 & 1.14 & 0.46 \\
\hline
\end{tabular}

For the three research sieve sizes, each have uniformity coefficient $(\mathrm{Cu})$ less than four, and Coefficient of gradation (Ce) approximately 1 implying that they each contain uniformly graded particles although with $5 \mathrm{~mm}$ and $7 \mathrm{~mm}$ sieve having a slightly larger range of particle size.

\subsection{Comparison of particles sizes}

Table 10 shows the particle sizes of garified sample from the three research sieves derived from the particle size distribution curve. From Table 10, the mean particle sizes from the three research sieves $3 \mathrm{~mm}, 5 \mathrm{~mm}$ and $7 \mathrm{~mm}$ are: $0.68,0.79$, and 0.88 with standard deviations of $0.31,0.41$ and 0.44 respectively. But do the particle sizes from each of these research sieves differ significantly? Table 10 shows the result of comparing the particle sizes from control sieve of $3 \mathrm{~mm}$ and that of the experimental sieve of $5 \mathrm{~mm}$.

Table 10: Particle sizes from control and

\begin{tabular}{cccc}
\multicolumn{4}{c}{ experimental sieves } \\
\hline \multirow{2}{*}{$\begin{array}{c}\text { Sample } \\
\text { point }\end{array}$} & $\begin{array}{c}\text { Control } \\
\text { sieve }\end{array}$ & \multicolumn{2}{c}{ Experimental sieve } \\
\cline { 2 - 4 } & $3 \mathrm{~mm}$ & $5 \mathrm{~mm}$ & $7 \mathrm{~mm}$ \\
\hline D10 & 0.31 & 0.33 & 0.34 \\
D20 & 0.38 & 0.40 & 0.44 \\
D30 & 0.47 & 0.54 & 0.64 \\
D40 & 0.58 & 0.64 & 0.80 \\
D50 & 0.68 & 0.80 & 0.90 \\
D60 & 0.79 & 0.94 & 0.99 \\
D70 & 0.94 & 1.18 & 1.30 \\
D80 & 1.25 & 1.52 & 1.66 \\
\hline Mean (M) & 0.68 & 0.79 & 0.88 \\
\hline SD & 0.30 & 0.41 & 0.44 \\
\hline
\end{tabular}

Table 11: Test of significance of particle sizes from sieve $3 \mathrm{~mm}$ and sieve $5 \mathrm{~mm}$

\begin{tabular}{lcccc}
\hline Sieve type & $\mathrm{N}$ & $\mathrm{M}$ & $\mathrm{SD}$ & $\mathrm{t}$-value \\
\hline $\begin{array}{l}\text { Control (3mm } \\
\text { aperture) }\end{array}$ & 8 & 0.68 & 0.31 & \\
\cline { 1 - 3 } $\begin{array}{l}\text { Experimental } \\
(5 \mathrm{~mm})\end{array}$ & 8 & 0.79 & 0.41 & \\
\hline
\end{tabular}

From the table, $\mathrm{N}$ is the sample size, $\mathrm{M}$ the mean of the sample and SD the standard deviation. Also from table 10, the calculated $\mathrm{t}$ - value of particle sizes from the control and that from the experimental sieve is 0.61 . From $t-$ table, the critical value at $5 \%$ level of significance and 14 degree of freedom is 2.15 . Since the calculated $t$-value of 0.61 is far less than the critical value of 2.15 , the hypothesis that the particle sizes from the control and the experimental sieve differ significantly is rejected. Thus the Garri particles from the control and that from the experimental sieve do not differ significantly in their sizes. Table 11 shows the result of comparing the particle sizes from control sieve of $3 \mathrm{~mm}$ and that of the experimental sieve of $7 \mathrm{~mm}$.

Table 12: Test of significance of particle sizes from sieve $3 \mathrm{~mm}$ and sieve $7 \mathrm{~mm}$

\begin{tabular}{lcccc}
\hline Sieve type & $\mathrm{N}$ & $\mathrm{M}$ & $\mathrm{SD}$ & $\mathrm{t}$-value \\
\hline $\begin{array}{l}\text { Control }(3 \mathrm{~mm} \\
\text { aperture })\end{array}$ & 8 & 0.68 & 0.31 & \\
\cline { 1 - 3 } $\begin{array}{l}\text { Experimental } \\
(5 \mathrm{~mm})\end{array}$ & 8 & 0.88 & 0.44 & \\
\hline
\end{tabular}

From the table, the calculated $t$ - value of particle size from the control and that from the experimental sieve is 1.1 , whereas the critical value at $5 \%$ level of significance and 14 degree of freedom is 2.15 . Since the calculated t-value of 1.1 is less than the critical value of 2.15 , the hypothesis that Garri particles from the control and the experimental sieves differ significantly in their sizes is also rejected. Thus the Garri particles from $3 \mathrm{~mm}$ sieve and that from the experimental $7 \mathrm{~mm}$ sieve do not differ significantly in their sizes.

\section{CONCLUSION}

Through experiment, the locally established sieve aperture of approximately $3 \mathrm{~mm}$ was modified to $5 \mathrm{~mm}$ and $7 \mathrm{~mm}$ with positive results. Throughput capacity at $5 \mathrm{~mm}$ aperture was higher by $24 \mathrm{~kg} / \mathrm{hr}$ over the $3 \mathrm{~mm}$ aperture. This was possible as the use of modified sieve at $5 \mathrm{~mm}$ aperture reduced sieving time from

Vol. 39, No. 4, April 2019

518 
4.1min to $2.6 \mathrm{~min}$. The test statistics of $F>4.256$ at $\mathrm{F}_{0.5,2}$, 9 shows that there is a statistical significant difference among the population means of the throughput capacities of the test sieves. The effective particle size D10, fineness modulus FM and Coefficient of gradation of the particles from the $3 \mathrm{~mm}$ aperture differ slightly from that of $5 \mathrm{~mm}$ but it does not translate to large difference. Considering that the calculated $t$ - value of particle sizes from the control and that from the experimental sieves are 0.61 and 1.1 respectively for $5 \mathrm{~mm}$ and $7 \mathrm{~mm}$ sieve, whereas the critical value at $5 \%$ level of significance and 14 degree of freedom is 2.15 , the observed difference with respect to the control sieve is not significant. This implies that the $5 \mathrm{~mm}$ and $7 \mathrm{~mm}$ sieves can be used to produce garri particles that do not differ significantly from that produced from the $3 \mathrm{~mm}$. Obviously, the notion held by the developer of traditional sieve and the processors who use them, that increasing the traditional sieve aperture beyond the approximately $3 \mathrm{~mm}$ aperture will render the particle size extra coarse and unacceptable is unsubstantiated. Traditional sieve aperture can therefore be modified from $3 \mathrm{~mm}$ to between $5 \mathrm{~mm}$ and $7 \mathrm{~mm}$ aperture inclusive with a positive effect of high throughput capacity at low input time and energy.

\section{REFERENCES}

[1] Wilhemina Q. J., Gayin, I. Y. and Plahar W.A. "Characteristics of Various Cassava Processing Methods and the Adoption Requirements in Ghana", Journal of Root Crops, Vol. 35, Number 1, 2009, pp. $59-68$.

[2] James, F.S. Screening Theory and Practice Triple/S Dynamics, Inc. Texas, 2012, pp1-7, 12-20

[3] George F. "Screening for Maximum Accuracy" https://www.911metallurgist.com. Accessed on August 6, 2016.

[4] RMIG "Calculation of Open area", http://rmig.com Len/technical+info/formulae, Accessed on July 4, 2018.

[5] Arthur G. "Sieve Mesh - Sizes, Testing Standards, Certification \& Calibration" https://www.google. com/search?q=Arthur G., Accessed on August 6, 2018.

[6] David S. An Introduction to the Principle and Importance of Proper Screening, Aggregates Equipment, Inc. Leola, 2015.
[7] Ogunsina B. S., Sanni, L. A. and Oladigbo C. "Development of a Rotary Pulverizer for Cassava Cake in Garri Production" Journal of Food Process Engineering, Vol.13, Number 8, 2008, pp. 783-797.

[8] Ahiakwo A. A. "Ergonomic Intervention and Sieve Aperture Effects on Musculoskeletal Discomfort in Dewatered Cassava Mash Sieving Process". Unpublished Ph.D Dissertation Department of Agricultural and Bio-resources Engineering, 2018, Michael Okpara University of Agriculture, Umudike.

[9] Uthman F "Design and Fabrication of Cassava Lump Breaking and Sieving Machine", Oasis Journal of Research and Development, Vol.1, Number 2, 2011, pp42-50

[10] Kudabo, E. A; Onipede, E. A and Adegbenro, O. A "Design, Fabrication and Performance Evaluation of an Improved Cassava Mash Sifter", Journal of Agriculture Vetnary Science, 2012. Vol. 4, Number 2, pp. $53-64$.

[11] Adetunji O.R., Dairo, O.U., Aiana, B and Osunlana A.S. "Development of an Improved Garri Sifting Machine", Pacific Journal of Science and Technology, Vol. 14, Number 2, 2013, pp. $67-75$.

[12] Abubakar M., Olawale J. O., Abdulkadir B. H., Dele S. J "The Design of a Pedal Driven Pulverizing and Sieving Machine for Dewatered Grated Cassava" International Journal of Scientific and Research Publications, Vol.4, Number 4, 2014, pp. $45-49$.

[13] Abiodun L.O., Oladipo N. O, and Bamidele B.L., "Development of NCAM Reciprocating Cassava Mash Sifter". International Journal of Basic and Applied Science, Vol.5, Number 3, 2016, pp. $10-$ 13.

[14] Burubai W and Etekpe, G.W. "Particle Size Characterization of Garri Powder", Advanced Journal of Agricultural Research, Vol. 2 Number 12, 2014 pp. 197 - 202.

[15] 'Mechanical Analysis of Soils", www.cememphis. edu/1101/notes/filtration/sieve analysis, Accessed July 10, 2018.

[16] "Screen Technology Group Inc.(2009/2016) Wire cloth and Wire Mesh Technical Reference Index" www.wovenwire.com, Accessed on August 6, 2018

[17]_Belleville Wire Cloth Co., Inc." www.bwire.com, Accessed on August 6, 2018

[18] Sayah, K.M and Singh, K.K. Unit Operations of Agricultural Processing. $2^{\text {nd }}$ ed. Vikas Publishing House PVT Ltd., Jangpura, New Delhi, 2009, pp 222 $-223$. 